\title{
Effect of intravitreal dexamethasone solution on the reduction of macular thickness in pseudophakic diabetic patients in a public hospital in Brazil: a randomized clinical trial
}

This article was published in the following Dove Press journal:

Clinical Ophthalmology

\section{Andre Luis A Fonseca \\ Heitor Panetta \\ Mauricio A Nascimento \\ Rodrigo Pessoa C Lira \\ Carlos Eduardo L Arieta}

Department of Ophthalmology, State University of Campinas, Campinas, São Paulo, Brazil
Correspondence: Andre Luis A Fonseca Department of Ophthalmology, State University of Campinas, Rua Vital Brasil, 25I - Cidade Universitária, Campinas, São Paulo I3083-888, Brazil

Tel +5519991359687

Email alayf@hotmail.com
Purpose: To determine the effect of short-term $4 \mathrm{mg} / \mathrm{mL}$ dexamethasone solution treatment in diabetic macular edema (DME).

Patients and methods: Twenty-seven pseudophakic diabetic patients with visual impairment caused by DME were randomized to receive $0.01 \mathrm{~mL}(40 \mu \mathrm{g}), 0.03 \mathrm{~mL}(120 \mu \mathrm{g})$ or $0.05 \mathrm{~mL}(200 \mu \mathrm{g})$ intravitreal dexamethasone solution. Eyes were evaluated in terms of macular thickness, best-corrected visual acuity (BCVA) and intraocular pressure (IOP) at 3, 7 and 28 days after injection (D).

Results: There was a significant reduction in macular thickness between D0 and D3 for all groups $(0.01 \mathrm{~mL}-P=0.008,0.03 \mathrm{~mL}-P=0.038$, and $0.05 \mathrm{~mL}-P=0.008)$. Between $\mathrm{D} 0$ and D7, a significant reduction in macular thickness was observed in $0.01 \mathrm{~mL}$ and $0.05 \mathrm{~mL}$ groups $(0.01$ $\mathrm{mL}-P=0.013$ and $0.05 \mathrm{~mL}-P=0.021$ ). Between $\mathrm{D} 0$ and $\mathrm{D} 28$, no significant reduction of macular thickness was observed for any group. Between D0 and D3, a significant improvement in BCVA in the $0.03 \mathrm{~mL}$ group $(P=0.028)$ was observed. Between D0 and D7, a significant improvement in BCVA was observed in $0.01 \mathrm{~mL}$ and $0.03 \mathrm{~mL}$ groups $(0.01 \mathrm{~mL}-P=0.018$ and $0.03 \mathrm{~mL}-P=0.027)$. Between D0 and D28, a significant improvement in BCVA was observed for the $0.01 \mathrm{~mL}$ group $(P=0.017)$. No significant differences in IOP measurements were observed for any group. Safety analysis revealed no serious ocular or systemic events.

Conclusion and relevance: Intravitreal dexamethasone solution is effective in reducing macular thickness secondary to DME in the short-term. Improvement in short-term visual acuity was observed. Although DME requires long-term treatment, it may be a low cost therapeutic option used in specific short-term situations.

Trial registration: NCT03608839 (http://www.clinicaltrials.gov).

Keywords: intravitreal dexamethasone solution, short-term treatment, diabetic macular edema, pseudophakic patients

\section{Introduction}

Diabetic macular edema (DME) is the main cause of visual impairment in patients with diabetes mellitus (DM). ${ }^{1}$ It has been estimated that DME would affect about $20 \%$ of individuals with type 1 and type 2 DM after 10 years of disease duration, rising up to $30 \%$ after 25 years. $^{2}$

In diabetic patients, hyperglycemia is the major risk factor contributing to the pathogenesis of DME. ${ }^{3}$ This process is related to 4 major biochemical pathways: polyol, advanced glycation endproducts, protein kinase $\mathrm{C}$ and hexosamine. ${ }^{3}$ All of 
these pathways lead to increased oxidative stress, inflammation, and vascular dysfunction. ${ }^{3}$ Oxidative stress and inflammation result in upregulation of growth factors and cytokines, such as vascularendothelial growth factor (VEGF), angiopoietins, tumor necrosis factor, interleukins, and matrix metalloproteinases, which contribute to breakdown of the blood-retinal barrier and development of DME. $^{3}$

The DME pathophysiological process is largely mediated by VEGF, but there is a growing appreciation that inflammation plays an important role in DME perpetuation and several cytokines besides VEGF are at high levels in this process. ${ }^{4-6}$ Evidence suggest that DME late phase may be more driven by inflammatory activity than by angiogenic action. ${ }^{4-6}$ This molecular pathway may explain why patients may demonstrate an inadequate response to anti-VEGF therapy in visual acuity gain. ${ }^{4-6}$

Several studies have revealed that anti-VEGF therapy, with or without macular laser treatment, is superior to laser treatment alone to improve visual acuity, while decreasing retinal thickness in patients with visual impairment caused by center-involved DME. ${ }^{7-12}$ However, complete resolution of DME has not been reported in all cases, despite intensive anti-VEGF and focal/grid laser therapies. ${ }^{7-12}$ Therefore, additional treatment strategies are necessary for patients with DME.

Corticosteroids promote downregulation of prostaglandins, cytokines and growth factors expression, such as VEGF. ${ }^{13}$ They also present an inhibitory action on leukostasis, adhesion and transmigration of leukocytes. ${ }^{6}$ In addition, they act in basal membrane endothelium of retinal capillaries and tight junctions, limiting vascular permeability and limiting leakage to the retinal interstitium. ${ }^{14}$

Intravitreal triamcinolone acetonide (IVTA) has been shown to be effective in improving the vision of patients with DME. ${ }^{7,15}$ In the DRCR net - protocol I study, which compared IVTA with ranibizumab as an adjunctive treatment to laser therapy, IVTA was as effective as ranibizumab in improving visual acuity in pseudophakic eyes; however, this was not observed in the entire study population, most likely due to cataract development. ${ }^{7,15}$

The $700 \mu \mathrm{g}$ dexamethasone intravitreal implant (Ozurdex ${ }^{\circledR}$; Allergan, Inc., Irvine, CA, USA) is an example of a sustained-release corticosteroid delivery system, developed with the aim to reduce the need for frequent intraocular injections. ${ }^{16}$ The Ozurdex ${ }^{\circledR}$ implant has been shown to provide a robust long-term improvement in vision and macular edema over a period of 3 years. ${ }^{17}$
Ozurdex has also demonstrated efficacy in the treatment of persistent DME, anti-VEGF-resistant DME, as well as in difficult-to-treat vitrectomized patients. ${ }^{18-21}$ Real-world evidence about repeated dexamethasone intravitreal implant in DME management suggests an average duration of action close to 5 months following a pro re nata strategy of treatment interesting about one-third of patients. $^{22}$ The use of repeated DEX implant administration revealed an acceptable balance between long-term efficacy and safety. ${ }^{22}$

Dexamethasone has a relative potency, which is 7 times greater than that of TA. ${ }^{23}$ In addition, dexamethasone is less lipophilic than TA, and hence does not accumulate in the trabecular meshwork and lens to the same extent; therefore suggesting a reduced risk of increased IOP and cataract progression. ${ }^{24}$

Although regression of DME and improvement in the level of retinopathy have been observed in VEGF inhibition clinical trials, several injections are often required, with many patients failing to demonstrate an adequate response despite repeated monthly injections (35\% of patients failure in gain $\geq 10$ letters and $55 \%$ of patients failure in gain $\geq 15$ letters). ${ }^{7-12}$

Therefore, intravitreal corticosteroids, alone or as a combination therapy with anti-VEGF agents, have been used in an attempt to improve patient outcome. .,17,25 $^{2}$ Recent data highlight the potential role of intravitreal corticosteroid therapy in the prevention of diabetic retinopathy (DR) progression, as well as to improve disease severity. $^{26,27}$

To the best of our knowledge, no studies evaluating short-term DME treatment with intravitreal $4 \mathrm{mg} / \mathrm{mL}$ dexamethasone solution in pseudophakic patients have been performed; therefore, its effect on macular thickness and visual acuity in these conditions is poorly understood.

The aim of this study was to determine the effect of intravitreal $4 \mathrm{mg} / \mathrm{mL}$ dexamethasone solution on macular thickness, visual acuity and IOP in the short-term treatment of DME, with short-term treatment defined as over a period of 3 days.

\section{Methods}

A Phase II, randomized, prospective, parallel, interventional study was performed. Data from DME diagnosed volunteers was collected and analyzed at the Department of Ophthalmology, State University of Campinas (UNICAMP), Brazil between May 2016 and December 2017. Informed written consent was obtained from all 
patients, and approved by the ethics committee of the Clinical Hospital of the State University of Campinas, with the study conducted in agreement with the Declaration of Helsinki for research involving human subjects. The study was registered with the trial identifier NCT03608839 at http://www.clinicaltrials.gov.

Inclusion criteria included: 1) aged 18 years or over; 2) diagnosis of type $2 \mathrm{DM}$; 3) patients with pseudophakic eyes; 4) presence of clinically significant DME according to ETDRS guidelines; 5) best-corrected visual acuity (BCVA) between 20/400 and 20/40; and 6) central macular thickness (CMT) of $\geq 300 \mu \mathrm{m}$, measured by spectraldomain optical coherence tomography (Spectralis ${ }^{\circledR}$; Heidelberg Engineering, Heidelberg, Germany). If both eyes met eligibility criteria, the eye with worse BCVA at baseline was used as the study eye.

Exclusion criteria were: 1) any treatment of DME in the previous 4 months; 2) pan-retinal photocoagulation (PRP) in the last 4 months or likelihood of necessity to undergo PRP during the next 6 months; 3) any ophthalmologic surgery performed in the last 4 months; 4) history of pars plana vitrectomy; 5) history of open-angle glaucoma or corticosteroid-induced elevated IOP that required anti-glaucoma or antihypertensive ocular treatments; and 6) IOP of $\geq 21 \mathrm{mmHg}$.

During the screening consultation, complete ophthalmic evaluation, including BCVA, slit-lamp biomicroscopy, applanation tonometry, fundus biomicroscopy, fluorescein angiography (Visucam NM/FA Carl Zeiss; Carl Zeiss Meditec, Dublin, CA, USA) and SD-OCT (Spectralis; Heidelberg Engineering) were performed. CMT was obtained through seven horizontal lines $\left(30^{\circ} \times 5^{\circ}\right.$ area $)$, centered on the fovea, with 1536 A scans per line at 240 $\mu \mathrm{m}$ intervals.

Patients were randomized via a 1:1:1 sequential allocation to receive $0.01 \mathrm{~mL}(40 \mu \mathrm{g}), 0.03 \mathrm{~mL}(120 \mu \mathrm{g})$, or 0.05 $\mathrm{mL}(200 \mu \mathrm{g})$ of the $4 \mathrm{mg} / \mathrm{mL}$ dexamethasone solution during the primary study visit (baseline). In subsequent visits, at 1, 3, 7, 14, 21, and 28 days, analysis via BCVA, slit-lamp biomicroscopy, applanation tonometry, fundus biomicroscopy, and SD-OCT (Spectralis; Heidelberg Engineering) was performed.

The current study used blocked randomization (3 groups with 9 members each); data were computer generated and stored in a locked cabinet until the end of the study period. Patients, study personnel responsible for intravitreal injections and those responsible for collecting BCVA, IOP, OCT data were blinded as to the patient study assignment.
Calculations based on effect size at 0.5 SDs of macular thickness between pre-injection (baseline) and the 3rd day post-injection indicated that a sample size consisting 27 subjects would be sufficient for detecting a difference of this magnitude with a power of 0.8 and a significance level of 0.05 (one-tailed).

The primary outcome was macular thickness at 3 and 7 days after intravitreal dexamethasone. The secondary outcomes were macular thickness at 28 days after intravitreal dexamethasone, BCVA and IOP at 3, 7 and 28 days after intravitreal dexamethasone.

In statistical analysis, continuous data were expressed as the mean $\pm \mathrm{SD}$ and range. Between-group differences of continuous variables were compared using Kruskal-Wallis one-way ANOVA, Wilcoxon Signed Ranks Test or MannWhitney U test when appropriate, and categorical variables were compared using Fisher-Freeman-Halton exact test. Analyses were performed using IBM SPSS Statistics version 20 (Chicago, IL, USA). Statistical significance was established when $P \leq 0.05$.

\section{Results}

All patients that volunteered to participate in the study were able to complete all stages. Twenty-seven eyes of 27 patients were included in the analysis, with each group containing 9 members. About $55.5 \%$ of patients were male, at a mean age of $67.9 \pm 7,33$ years, with the right eye being the study eye in $55.5 \%$ of cases. At baseline, $77.7 \%$ of patients presented moderate non-proliferative DR, with $22.3 \%$ of patients having previously been submitted to scatter laser photocoagulation, and no patients presented severe non-proliferative or proliferative DR. Patients had a diagnosis of DM for at least 6 years, with some having carried the disease for up to 31 years, at an average of 18.1 years. $62.9 \%$ of patients reported having never undergone any treatment for DME, while $22.2 \%$ had already undergone anti-VEGF intravitreal injections, with $14.9 \%$ having been submitted to macular laser therapy.

At baseline, mean BCVA was 53.2 \pm 16.61 letters; CMT was $537.4 \pm 196.94 \mu \mathrm{m}$ and IOP was $12.2 \pm 2.39 \mathrm{mmHg}$. Retinal macular structural features identified on OCT: epiretinal membrane in $37 \%$ of patients, subretinal fluid in $14.8 \%$, microaneurysms in the foveal region in $92.5 \%$, and posterior vitreous detachment in $33.3 \%$. Table 1 represents the baseline clinical characteristics of 27 patients included in the study who were randomized to receive intravitreal $0.01 \mathrm{~mL}(40 \mu \mathrm{g}), 0.03 \mathrm{~mL}(120 \mu \mathrm{g})$ or 
Table I Baseline characteristics of 27 subjects with diabetic macular edema randomized to receive intravitreal $0.01 \mathrm{~mL}(40 \mu \mathrm{g}), 0.03$ $\mathrm{mL}(120 \mu \mathrm{g})$, or $0.05 \mathrm{~mL}(200 \mu \mathrm{g})$ of the $4 \mathrm{mg} / \mathrm{mL}$ dexamethasone solution

\begin{tabular}{|c|c|c|c|c|}
\hline & $40 \mu g(n=9)$ & $120 \mu g(n=9)$ & $200 \mu g(n=9)$ & $\mathbf{P}$ \\
\hline Age (years): mean (SD), median & $67(6), 66$ & $66(8), 66$ & 7I (7), 70 & $0.226^{\mathrm{a}}$ \\
\hline Sex - male & 6 & 5 & 4 & $0.638^{\mathrm{b}}$ \\
\hline Eye - right & 3 & 7 & 5 & $0.165^{\mathrm{b}}$ \\
\hline ERM & 5 & 3 & 2 & $0.329^{b}$ \\
\hline SRF & I & 2 & I & $0.746^{\mathrm{b}}$ \\
\hline MA & 8 & 8 & 9 & $0.583^{b}$ \\
\hline PVD & 2 & 2 & 5 & $0.223^{b}$ \\
\hline CMT $(\mu \mathrm{m})$ : mean $(\mathrm{SD})$, median & 527 (154), 459 & 630 (255), 548 & 453 (140), 398 & $0.163^{\mathrm{a}}$ \\
\hline BCVA (letters): mean (SD), median & $52(14), 48$ & 47 (19), 47 & $60(15), 67$ & $0.343^{\mathrm{a}}$ \\
\hline BCVA (Snellen) & $\cong 0.20$ & $\cong 0.16$ & $\cong 0.32$ & \\
\hline IOP $(\mathrm{mmHg})$ : mean (SD), median & $12(2), 12$ & $12(3), 12$ & $12(3), 11$ & $0 ., 270^{\mathrm{a}}$ \\
\hline
\end{tabular}

Notes: ${ }^{\text {a}}$ Kruskal-Wallis one-way ANOVA, ${ }^{\text {b}}$ Fisher's exact test. BCVA based on ETDRS charts.

Abbreviations: ERM, epiretinal membrane; SRF, subretinal fluid; MA, microaneurysms in foveal region; PVD, posterior vitreal detachment; CMT, central macular thickness; BCVA, best-corrected visual acuity; IOP, intraocular pressure; ETDRS, Early Treatment Diabetic Retinopathy Study.

$0.05 \mathrm{~mL}(200 \mu \mathrm{g})$ of the $4 \mathrm{mg} / \mathrm{mL}$ dexamethasone solution.

The patients assigned to each group are comparable in terms of the following variables: age, macular thickness, BCVA and IOP. However, there were random non-significant imbalances: members of the $0.05 \mathrm{~mL}$ dexamethasone group were older, had lower macular thickness and better best correct visual acuity compared to the other groups, while members of the $0.03 \mathrm{~mL}$ dexamethasone group had greater macular thickness than the others. Furthermore, individual retinal macular structural features are also comparable: posterior vitreous detachment, subretinal fluid, epiretinal macular membrane, as well as microaneurysms in the foveal region. Individual data of each patient with CMT, BCVA and IOP will be publicly available at http://www.clinicaltrials.gov, trial registration NCT03608839.

Overall analysis of all volunteers treated with $4 \mathrm{mg} / \mathrm{mL}$ dexamethasone solution revealed a significant reduction in macular thickness between baseline and 3rd day post-injection $(P<0.001)$ and baseline and 7 th day post-injection $(P=0.004)$, as well as a significant improvement of BCVA between baseline and 3 days post-injection $(P=0.010)$, baseline and 7 days post-injection $(P=0.001)$, as well as baseline and 28 days post-injection $(P=0.008)$. The mean reduction of macular thickness after 3 days of treatment was $21.16 \%$, and $12.85 \%$ after 7 days. Figure 1 represents mean change in macular thickness from baseline over time for the overall

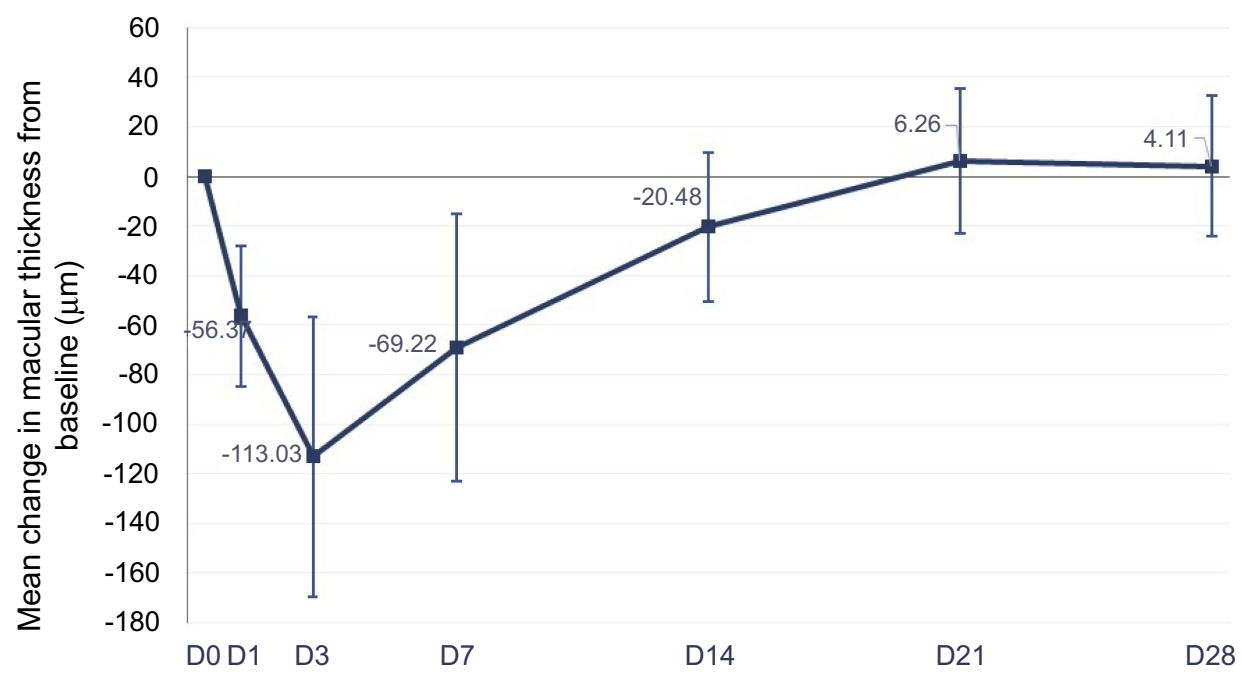

Figure I Mean change and $95 \% \mathrm{Cl}$ in macular thickness from baseline over time for the overall cohort, in $\mu \mathrm{m}$. Abbreviation: D, days after injection. 
cohort; Figure 2 represents mean change in macular thickness from baseline over time to each group.

Figure 3 represents mean change in visual acuity from baseline over time for the overall cohort; Figure 4 represents mean change in visual acuity from baseline over time for each group.

In group analysis of participants treated with $0.01 \mathrm{~mL}$ dexamethasone solution, there was significant reduction of macular thickness between D0 and D3 $(P=0.008)$ and between D0 and D7 $(P=0.013)$, while no significant reduction was observed between D0 and D28 $(P=0.678)$. No significant improvement in BCVA was revealed between
$\mathrm{D} 0$ and $\mathrm{D} 3(P=0.077)$, despite a significant difference was noticed between D0 and D7 $(P=0.018)$ and D0 and D28 $(P=0.017)$. There was no significant change in IOP measurements between D0 and D3 $(P=0.887)$, D0 and D7 $(P=0.391)$ or between D0 and D28 $(P=0.414)$.

In group analysis of participants treated with $0.03 \mathrm{~mL}$ dexamethasone solution revealed a significant reduction in macular thickness between D0 and D3 $(P=0.038)$, while no significant reduction was seen between D0 and D7 $(P=0.441)$ and between D0 and D28 $(P=0.953)$. A significant improvement in BCVA was revealed between D0 and D3 $(P=0.028)$ and between D0 and D7 $(P=0.027)$, while

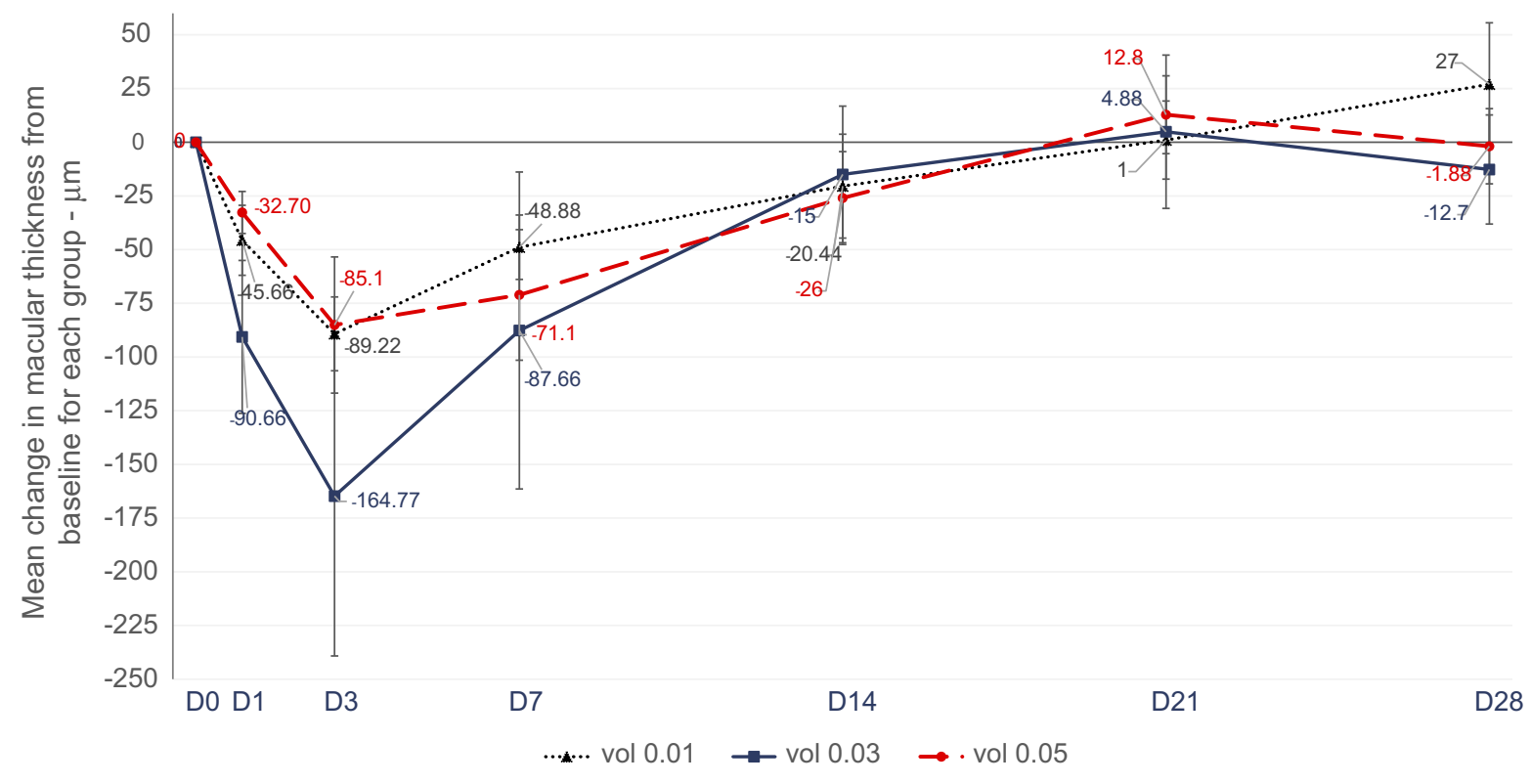

Figure 2 Mean change and $95 \% \mathrm{Cl}$ in macular thickness from baseline over time for each group, in $\mu \mathrm{m}$. Abbreviation: $\mathrm{D}$, days after injection.

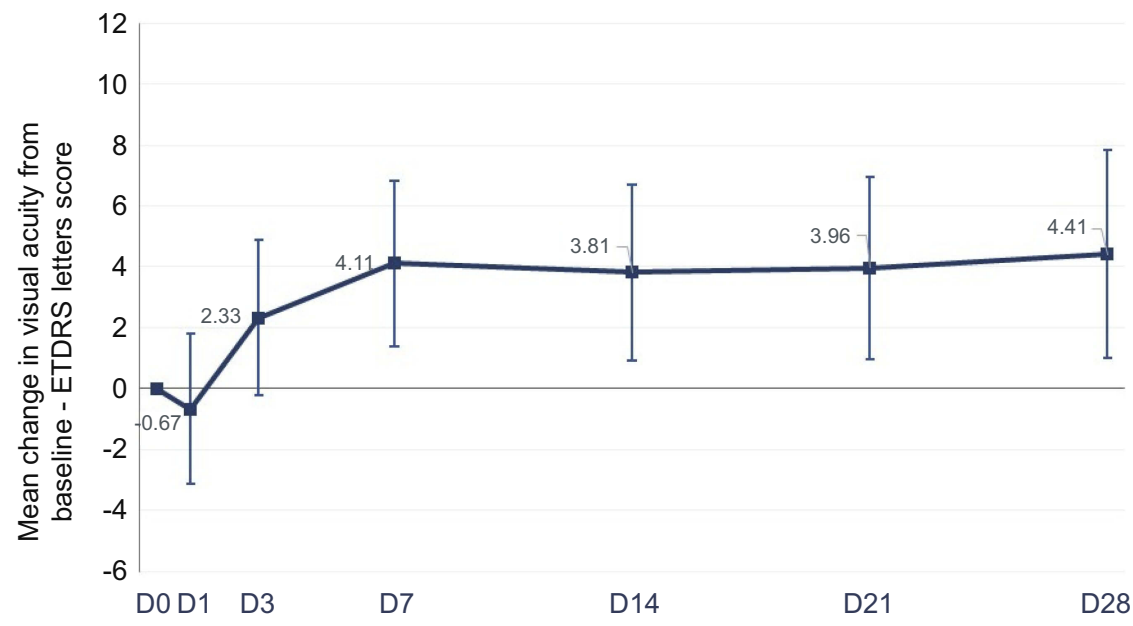

Figure 3 Mean change and $95 \% \mathrm{Cl}$ in visual acuity from baseline over time for the overall cohort, in ETDRS letter score.

Abbreviations: D, days after injection; ETDRS, Early Treatment Diabetic Retinopathy Study. 


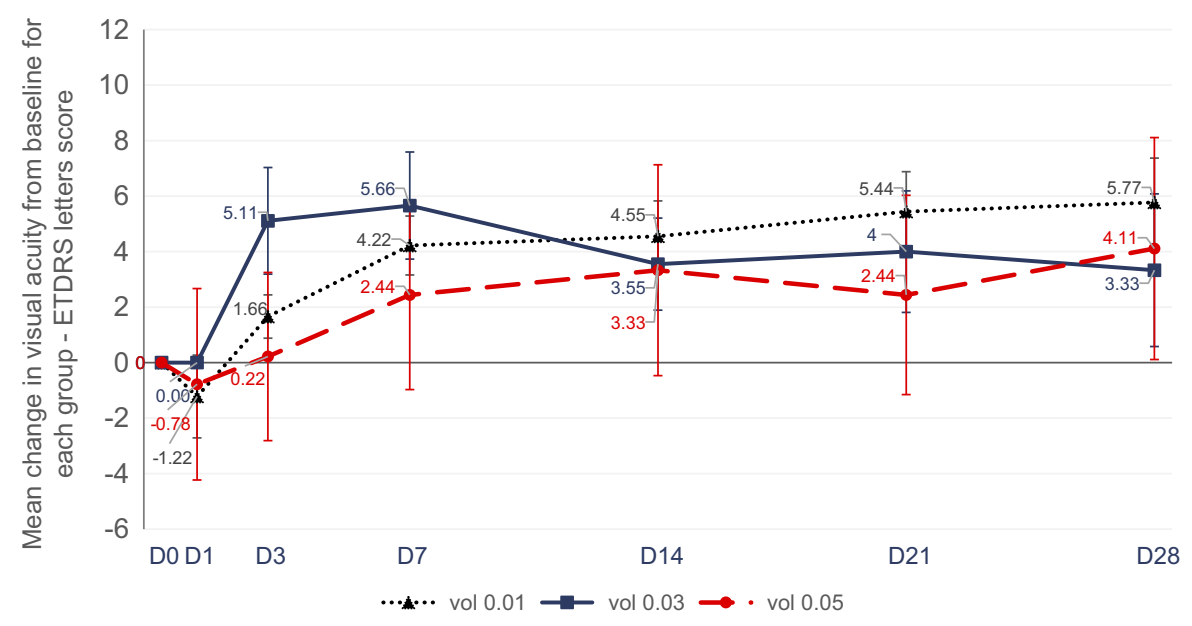

Figure 4 Mean change and $95 \% \mathrm{Cl}$ in visual acuity from baseline over time for each group, in ETDRS letter score.

Abbreviations: D, days after injection; ETDRS, Early Treatment Diabetic Retinopathy Study.

no significant improvement was observed between D0 and D28 $(P=0.249)$. No significant differences in IOP measurements were observed between D0 and D3 $(P=0$. 773), D0 and D7 $(P=0.603)$ or between D0 and D28 $(P=0.107)$.

Finally, in the subgroup analysis of participants treated with $0.05 \mathrm{~mL}$ dexamethasone solution, a significant reduction of macular thickness was observed between D0 and D3 $(P=0.008)$ and D0 and D7 $(P=0.021)$, while no significant reduction of was seen between D0 and D28 $(P=0.859)$. No significant improvement of BCVA was revealed between D0 and D3 $(P=0.600)$, between D0 and D7 $(P=0.235)$ and between D0 and D28 $(P=0.260)$. No significant differences in IOP measurements were observed for D0 and D3 $(P=0.348), \quad$ D0 and D7 $(P=0.733)$ or between D0 and D28 $(P=0.488)$.
Safety analysis revealed no serious ocular or systemic events during the current study. There were no reports of retinal detachment, corneal disturbance, endophthalmitis or significant IOP elevation. The highest mean IOP increase occurred on D1 $(0.9 \mathrm{mmHg})$, which subsequently normalized to baseline levels.

Figure 5 represents mean change in IOP from baseline over time for the overall cohort; Figure 6 represents mean change in IOP from baseline over time for each group.

\section{Discussion}

This is an original study that investigated the short-term effects and safety profile of $4 \mathrm{mg} / \mathrm{mL}$ dexamethasone solution on DME treatment. It is important to note that to date, no data is available in the medical literature that

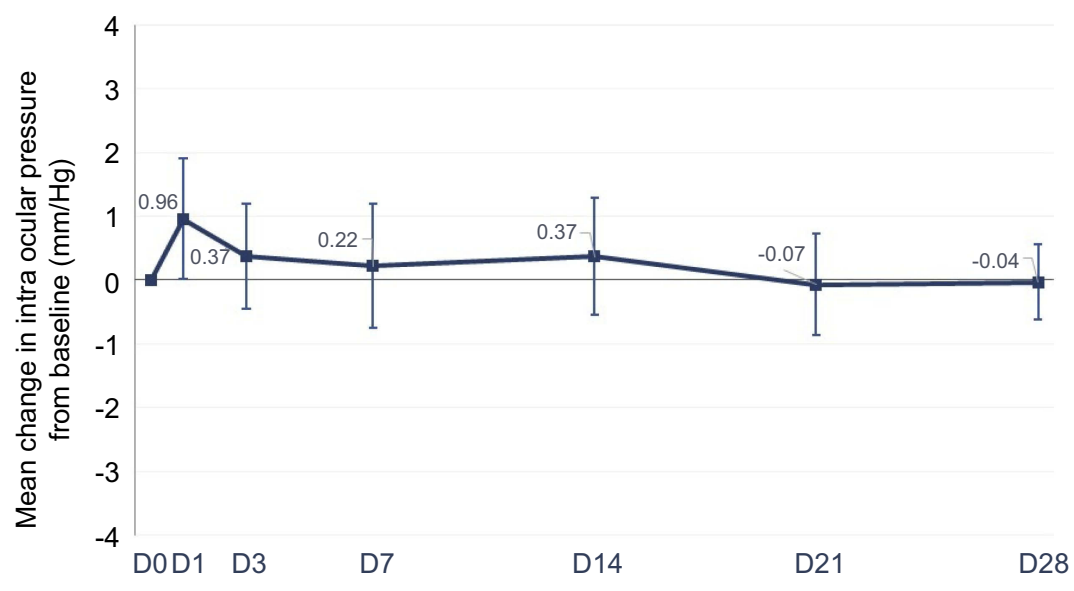

Figure 5 Mean change and $95 \% \mathrm{Cl}$ in intraocular pressure (IOP) from baseline over time for the overall cohort, in $\mathrm{mmHg}$. 


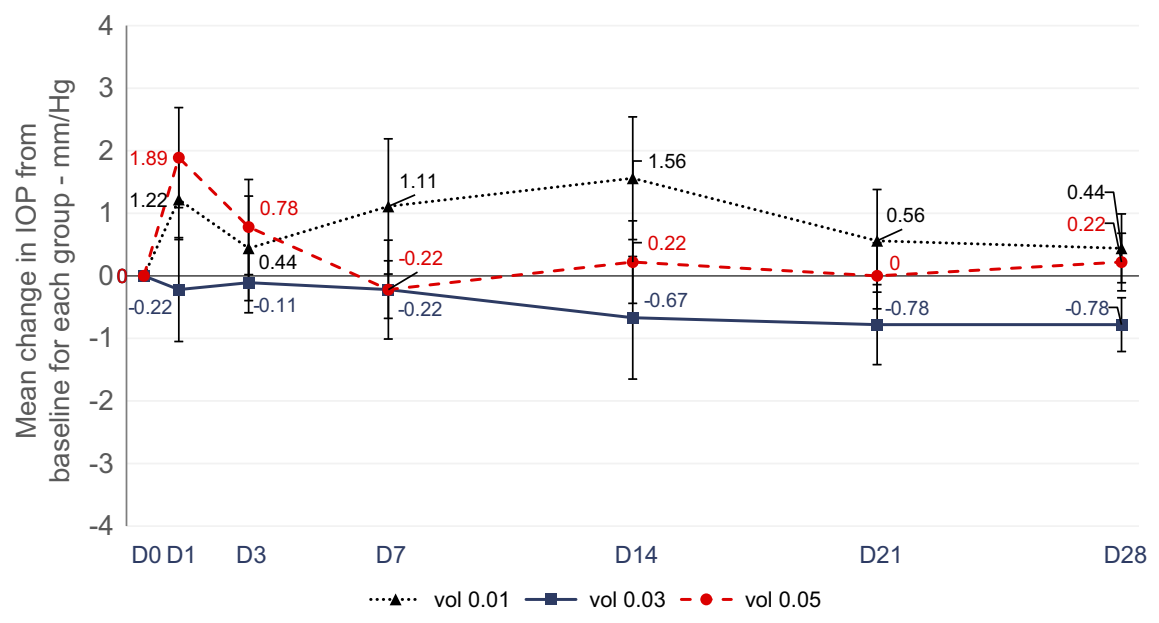

Figure 6 Mean change and $95 \% \mathrm{Cl}$ in intraocular pressure (IOP) from baseline over time for each group, in $\mathrm{mmHg}$.

Abbreviation: $\mathrm{D}$, days after injection.

describes an appropriate course and duration of treatment for aforementioned condition.

In the current study, analysis of change in macular thickness revealed a significant reduction between D0 and D3 and D0 and D7 post-treatment. However, although macular thickness returned to its original baseline value 28 days after initial therapy (541.8 vs $537.4 \mu \mathrm{m})$, BCVA data revealed a significant improvement between D0 and D3, D0 and D7, and D0 and D28, with an average gain of 4.4 ETDRS letters in 28 days. The baseline clinical characteristics of the participants involved in the study lead one to believe that almost all patients presented chronic DME. One may be pondering that the study may have provided a better visual acuity result had the selected patients presented a less chronic profile for DME.

The results were enlightening regarding dexamethasone solution action on macular thickness in DME, since in study planning it was speculated that the aforementioned action would present effect of just a few hours. The results showed a significant macular thickness reduction ( $12.85 \%$ over the initial values for the whole cohort) 7 days after the intravitreal injection, as shown in Figure 1.

Chang-Lin et al investigated the pharmacokinetics and pharmacodynamics of a sustained-release dexamethasone intravitreal implant in monkey eyes. ${ }^{28}$ Dexamethasone was quantified by liquid chromatography-tandem mass spectrometry, and cytochrome P450 3A8 gene expression was analyzed by reverse transcription-polymerase chain reaction. ${ }^{28} \mathrm{It}$ revealed sustained levels of dexamethasone and continued biological activity for 6 months after initial treatment, with peak drug levels obtained during the first 2 months. ${ }^{28}$ Maximum vitreous dexamethasone level was $213 \mathrm{ng} / \mathrm{mL}$ on day $60 .{ }^{28}$ These mentioned data corroborate our findings that dexamethasone solution, even when used $0.01 \mathrm{~mL}(40 \mu \mathrm{g})$, is effective in reducing DME in the short term.

Another clinical study based on the treatment of DME with dexamethasone implant revealed a maximum visual acuity gain and greatest decrease in retinal thickness and total macular volume during the 2 nd month after initial treatment, both in naïve and refractory groups. ${ }^{29}$

A systematic review demonstrated that the IVTA injection was more effective in improving visual acuity after 3 months when compared with no treatment or treatment with a sub-tenon triamcinolone acetonide injection; however, said effect did not persist for 6 months in either treatment modality. ${ }^{30}$ Likewise, IVTA injection was more effective in reducing CMT values in both comparison groups at 3 months; while at 6 months the above benefit was observed between the IVTA injection and no treatment groups, only. ${ }^{30}$

The DRCR net - protocol B study compared IVTA 1 $\mathrm{mg}$ and $4 \mathrm{mg}$ with laser photocoagulation in DME treatment. ${ }^{31}$ After 2 years of follow-up, laser photocoagulation was more effective and showed less adverse effects than the two triamcinolone groups, probably due cataract development. ${ }^{31}$ Nevertheless, in DRCR net - protocol I study, IVTA was as effective as ranibizumab in improving visual acuity in pseudophakic eyes. ${ }^{7,15}$

No significant adverse events were described for the intravitreal injection procedures or medication used, including retinal detachment, corneal disturbance or endophthalmitis. An increase in IOP on D1 (mean of 0.9 $\mathrm{mmHg}$ ) with subsequent normalization to baseline levels was observed, with no patient requiring ocular 
antihypertensive treatment during the study period. In the MEAD Study, approximately one-third of patients in all DEX implant treatment groups presented a clinically significant increase in IOP that subsequently required treatment. ${ }^{17}$ However, over a period of 3 years, no cumulative effect of the Dex implant on IOP was observed. ${ }^{17}$ As only one intravitreal dexamethasone solution injection was performed in the study, adverse events of frequent administration are unknown.

The primary limitation of this study is the absence of comparison parameters due to the lack of previous studies on this subject and no electrophysiological assessment of the retina before and after intravitreal dexamethasone solution $4 \mathrm{mg} / \mathrm{mL}$. Kwak et al evaluated retinal toxicity induced by dexamethasone sodium phosphate in doses ranging from 440 to $4000 \mu \mathrm{g}$ in rabbit eyes. ${ }^{32}$ After the $440 \mu \mathrm{g}$ dose, a transient increase in staining of the Muller cells was observed, which normalized after 2 days. ${ }^{32}$ Progressively higher doses resulted in an increasing spectrum of disorganization in Muller and other retinal cells. ${ }^{32}$ Based on the mentioned data, we considered $4 \mathrm{mg} / \mathrm{mL}$ dexamethasone solution maximum safe dose of $200 \mu \mathrm{g}$ $(0.05 \mathrm{~mL})$ in study planning.

The DRCR net - protocol U study compared ranibizumab monotherapy with ranibizumab associated with intravitreal dexamethasone implant $700 \mu \mathrm{g}$ for the treatment of persistent DME. $^{25}$ This study revealed that the addition of Ozurdex to continued ranibizumab therapy did not result in improvement of visual acuity in subjects with persistent DME at the 24-week analysis when compared to ranibizumab continuous monotherapy. ${ }^{25}$ However, a significant reduction in macular thickness was observed with combined therapy as well as a significant improvement of 15 letters or more when compared to ranibizumab monotherapy, suggesting a future trend for use of combination therapies in the treatment of DME. ${ }^{25}$ Subgroup analysis, considering crystalline status, revealed greater improvement in visual acuity with combined therapy in pseudophakic patients compared to ranibizumab monotherapy. ${ }^{25}$ To eliminate the confounding factor of lens status on visual acuity gains, the present study included pseudophakic patients only.

Based on the aforementioned observations, one may speculate that intravitreal $4 \mathrm{mg} / \mathrm{mL}$ dexamethasone solution may be indicated for diabetic patients in the following situations: to reduce macular thickness before macular photocoagulation laser therapy; to decrease the inflammatory response that causes increase of macular thickness following scatter photocoagulation laser therapy; to reduce macular edema before surgical peeling of epiretinal membranes; to reduce the initial postoperative inflammatory response when injected intraoperatively during cataract surgeries or peeling of epiretinal membranes or in the adjunctive treatment of neovascular glaucoma with low cost when compared to anti-VEGF therapy; or in combination therapies with anti-VEGF in the treatment of DME.

In summary, the current study demonstrated that $4 \mathrm{mg} / \mathrm{mL}$ dexamethasone solution, even when used $0.01 \mathrm{~mL}(40 \mu \mathrm{g})$, is effective in reducing DME in the short term. Moreover, improvement in short-term visual acuity was observed. Despite that one should consider that DME is a disease that usually requires extensive treatment to obtain satisfactory visual acuity results, it may be a therapeutic option used in specific short-term situations in the adjuvant treatment of DME in order to obtain better therapeutic responses with low cost as it is widely available in clinics and hospitals.

\section{Disclosure}

The authors report no conflicts of interest in this work.

\section{References}

1. Bandello F, Battaglia Parodi M, Lanzetta P, et al. Diabetic macular edema. Dev Ophthalmol. 2010;47:73-110.

2. Williams R, Airey M, Baxter H, Forrester J, tKennedy-Marin T, Girach A. Epidemiology of diabetic retinopathy and macular oedema: a systematic review. Eye (Lond). 2004;18(10):963-983. doi:10.1038/ sj.eye. 6701476

3. Das A, McGuire PG, Rangasamy S. Diabetic macular edema: pathophysiology and novel therapeutic targets. Ophthalmology. 2015;122 (7):1375-1394. doi:10.1016/j.ophtha.2015.03.024

4. Daruich A, Matet A, Moulin A, et al. Mechanisms of macular edema: beyond the surface. Prog Retin Eye Res. 2018;63(3):20-68. doi:10.1016/j.preteyeres.2017.10.006

5. Urias EA, Urias GA, Monickaraj F, McGuire P, Das A. Novel therapeutic targets in diabetic macular edema: beyond VEGF. Vision Research. 2017;139:221-227. doi:10.1016/j.visres.2017.06.015

6. Zhang X, Wang N, Schachat AP, Bao S, Gillies MC. Glucocorticoids: structure, signaling and molecular mechanisms in the treatment of diabetic retinopathy and diabetic macular edema. Curr Mol Med. 2014;14:376-384.

7. Elman MJ, Aiello LP, Beck RW, et al. Diabetic retinopathy clinical research network. randomized trial evaluating ranibizumab plus prompt or deferred laser or triamcinolone plus prompt laser for diabetic macular edema. Ophthalmology. 2010;117(6):1064-1077. doi:10.1016/j.ophtha.2010.02.031

8. Nguyen QD, Brown DM, Marcus DM, et al. RISE and RIDE research group. Ranibizumab for diabetic macular edema: results from 2 phase III randomized trials: RISE and RIDE. Ophthalmology. 2012;119(4):789801. doi:10.1016/j.ophtha.2011.12.039

9. Mitchell P, Bandello F, Schmidt-Erfurth U, et al. RESTORE study group. The RESTORE study: ranibizumab monotherapy or combined with laser versus laser monotherapy for diabetic macular edema. Ophthalmology. 2011;118(4):615-625. doi:10.1016/j.ophtha.2011.01. 031 
10. Korobelnik JF, Do DV, Schmidt-Erfurth U, et al. Intravitreal aflibercept for diabetic macular edema. Ophthalmology. 2014;121 (11):2247-2254. doi:10.1016/j.ophtha.2014.05.006

11. Massin P, Bandello F, Garweg JG, et al. Safety and efficacy of ranibizumab in diabetic macular edema (RESOLVE study). Diabetes Care. 2010;33:2399-2405. doi:10.2337/dc10-0493

12. Nguyen QD, Shah SM, Khwaja AA, et al. Two-year outcomes of the ranibizumab for edema of the macula in diabetes (READ-2) study. Ophthalmology. 2010;117(11):2146-2151. doi:10.1016/j.ophtha.2010.08. 016

13. Sohn HJ, Han DH, Kim IT, et al. Changes in aqueous concentrations of various cytokines after intravitreal triamcinolone versus bevacizumab for diabetic macular edema. Am J Ophthalmol. 2011;152:686694. doi:10.1016/j.ajo.2011.03.033

14. Vujosevic S, Torresin T, Bini S, et al. Imaging retinal inflammatory biomarkers after intravitreal steroid and anti-VEGF treatment in diabetic macular oedema. Acta Ophthalmol. 2017;95:464-471. doi:10.1111/aos.13294

15. Elman MJ, Bressler NM, Qin H, et al. Diabetic retinopathy clinical research network. Expanded 2-year follow-up of ranibizumab plus prompt or deferred laser or triamcinolone plus prompt laser for diabetic macular edema. Ophthalmology. 2011;118:609-614. doi:10.1016/j.ophtha.2010.12.033

16. Ciulla TA, Harris A, McIntyre N, Jonescu-Cuypers C. Treatment of diabetic macular edema with sustained-release glucocorticoids: intravitreal triamcinolone acetonide, dexamethasone implant, and fluocinolone acetonide implant. Expert Opin Pharmacother. 2014;15:953959. doi:10.1517/14656566.2014.896899

17. Boyer DS, Yoon YH, Bellfort R Jr, et al. Ozurdex MEAD study group Three-year, randomized, sham-controlled trial of dexamethasone intravitreal implant in patients with diabetic macular edema. Ophthalmology. 2014;121(10):1904-1914. doi:10.1016/j.ophtha.2014. 04.024

18. Pacella E, Vestri AR, Muscella R, et al. Preliminary results of an intravitreal dexamethasone implant (Ozurdex) in patients with persistent diabetic macular edema. Clin Ophthalmol. 2013;7:1423-1428. doi:10.2147/OPTH.S48364

19. Lazic R, Lukic M, Boras I, et al. Treatment of anti-vascular endothelial growth factor-resistant diabetic macular edema with dexamethasone intravitreal implant. Retina. 2014;34(4):719-724. doi:10.1097/ IAE.0b013e3182a48958

20. Cicinelli MV, Cavalleri M, Querques L, Rabiolo A, Bandello F, Querques G. Early response to ranibizumab predictive of functional outcome after dexamethasone for unresponsive diabetic macular edema. $B r \quad J$ Ophthalmol. 2017;101:1689-1693. doi:10.1136/ bjophthalmol-2017-310242

21. Boyer DS, Faber D, Gupta S, et al. Ozurdex champlain study group. Dexamethasone intravitreal implant for treatment of diabetic macular edema in vitrectomized patients. Retina. 2011;31(5):915-923 doi:10.1097/IAE.0b013e318206d18c
22. Bucolo C, Gozzo L, Longo L, Mansueto S, Vitale DC, Drago F. Long-term efficacy and safety profile of multiple injections of intravitreal dexamethasone implant to manage diabetic macular edema: a systematic review of real-world studies. Journal of Pharmacological Sciences. 2018;138:219-232. doi:10.1016/j. jphs.2018.11.001

23. Whitcup SM, Cidlowski JA, Csaky KG, Ambati J. Pharmacology of corticosteroids for DME. Invest Ophthalmol Vis Sci. 2018;59:1-12. doi:10.1167/iovs. 17-22259

24. Thakur A, Kadam R, Kompella UB. Trabecular meshwork and lens partitioning of corticosteroids: implications for elevated intraocular pressure and cataracts. Arch Ophthalmol. 2011;129(7):914-920. doi:10.1001/archophthalmol.2011.39

25. Maturi RK, Glassman AR, Liu D, et al. Diabetic retinopathy clinical research network. Effect of adding dexamethasone to continued ranibizumab treatment in patients with persistent diabetic macular edema: a DRCR network phase 2 randomized clinical trial. JAMA Ophthalmol. 2018;136(1):29-38. doi:10.1001/jamaophthalmol.2017. 4914

26. Iglicki M, Zur D, Busch C, Mali O, Loewenstein A. Progression of diabetic retinopathy severity after treatment with dexamethasone implant: a 24 month cohort study the "DR- pro DEX study". Acta Diabetologica. 2018;55:541-547. doi:10.1007/s00592-018-1117-z

27. Wykoff CC, Chakravarthy U, Campochiaro PA, Bailey C, Green K, Cunha-Vaz J. Long term effects of intravireal $0,19 \mathrm{mg}$ fluocinolone acetonide implanto $\mathrm{n}$ progression and regression of diabetic retinopathy. Ophthalmology. 2017;124:440-449. doi:10.1016/j.ophtha.2016. 11.034

28. Chang-lin JE, Attar M, Acheampong AA, et al. Pharmacokinetics and pharmacodynamics of a sustained release dexamethasone intravitreal implant. IOVS. 2011;52(1):80-86.

29. Escobar-Barranco JJ, Pina-Marín B, Fernandez-Bonet M. Dexamethasone implants in patients with naïve or or refractory diffuse diabetic macular edema. Opthalmologica. 2015;233:176185. doi: $10.1159 / 000371770$

30. Yilmaz T, Weaver CD, Gallagher MJ, et al. Intravitreal triamcinolone acetonide injection for treatment of refractory diabetic macular edema: a systematic review. Ophthalmology. 2009;116(5):902-911. doi:10.1016/j.ophtha.2009.02.002

31. Elman MJ, Raden RZ, Sloan MD, et al. Diabetic retinopathy clinical research network. A randomized trial comparing intravitreal triamcinolone acetonide and focal/grid photocoagulation for diabetic macular edema. Ophthalmology. 2008;115(9):1447-1449. doi:10.1016/j. ophtha.2008.06.015

32. Kwak HW, D'Amico DJ. Evaluation of the retinal toxicity and phamacokinetics of dexamethasone after intravitreal injection. Arch Ophthalmol. 1992;110(2):259-266. doi:10.1001/archopht.1992.0108 0140115038
Clinical Ophthalmology

\section{Publish your work in this journal}

Clinical Ophthalmology is an international, peer-reviewed journal covering all subspecialties within ophthalmology. Key topics include: Optometry; Visual science; Pharmacology and drug therapy in eye diseases; Basic Sciences; Primary and Secondary eye care; Patient Safety and Quality of Care Improvements. This journal is indexed on PubMed
Central and CAS, and is the official journal of The Society of Clinical Ophthalmology (SCO). The manuscript management system is completely online and includes a very quick and fair peer-review system, which is all easy to use. Visit http://www.dovepress.com/ testimonials.php to read real quotes from published authors. 